\title{
Correction to: Processing, dielectric and electrical characteristics of strontium-modified $\mathrm{Ca}_{1} \mathrm{Cu}_{3} \mathrm{Ti}_{4} \mathrm{O}_{12}$
}

\author{
Madhusmita Sahu ${ }^{1} \cdot$ Arijit Mitra $^{2}$ - R. N. P. Choudhary ${ }^{1}$ - B. K. Roul ${ }^{3}$
}

Published online: 10 August 2018

C Springer-Verlag GmbH Germany, part of Springer Nature 2018

Correction to: Applied Physics A (2018) 124:533

https://doi.org/10.1007/s00339-018-1952-3

Dear readers,

Due to a technical error, Fig. 7 in the original article was not displayed completely.

It would be correct in the form depicted here:

The original article can be found online at https://doi.org/10.1007/ s00339-018-1952-3.

Madhusmita Sahu

mssahu1592@gmail.com

1 Department of Physics, Siksha O Anusandhan (Deemed to be University), Bhubaneswar, Odisha 751030, India

2 School of Basic Sciences, Indian Institute of Technology, Bhubaneswar, Odisha, India

3 Institute of Materials Science, Bhubaneswar, Odisha, India
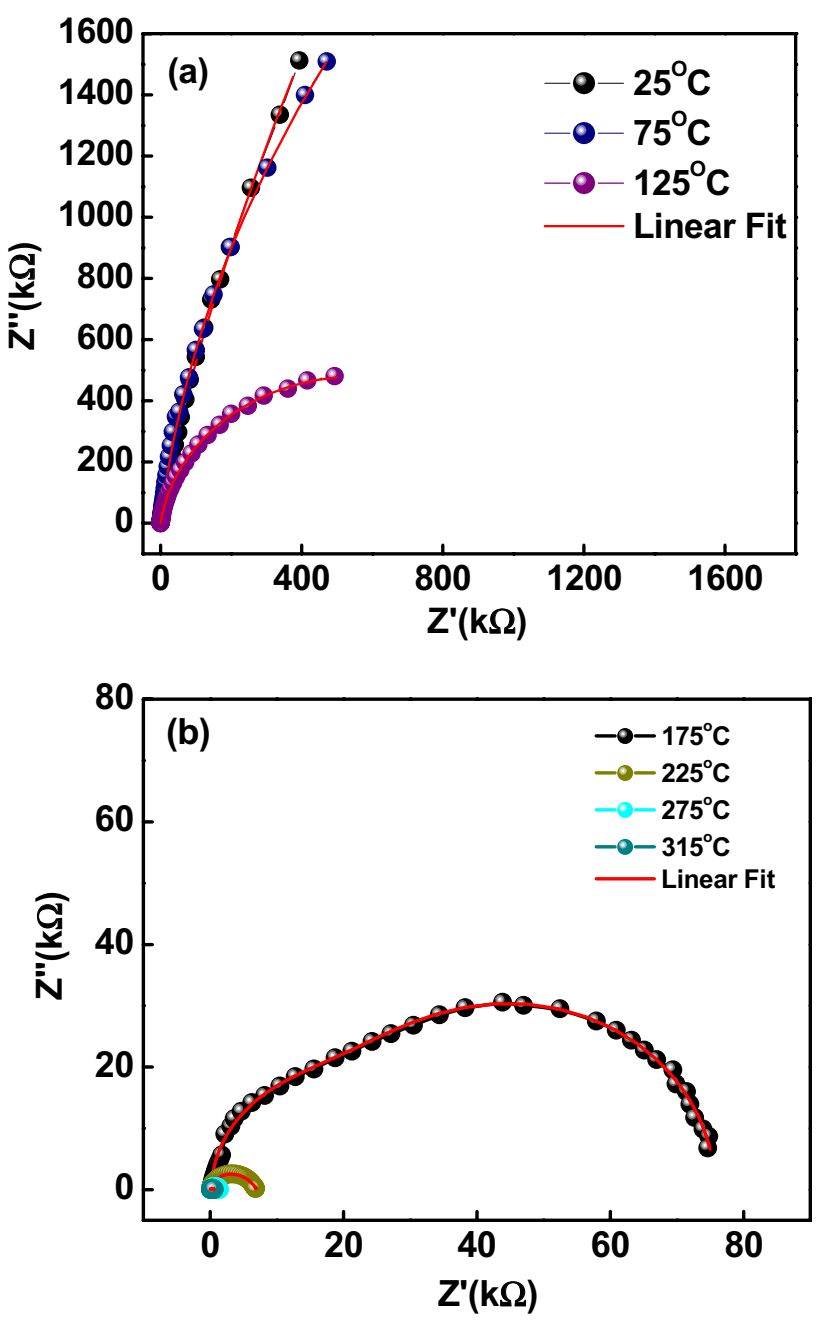

(c)

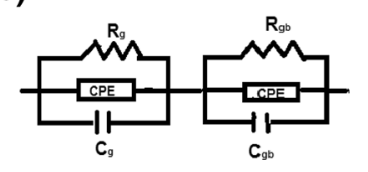

(d)

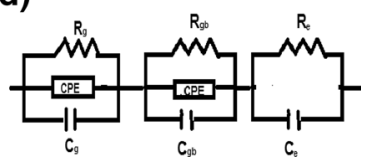

Please excuse this mistake. 